\title{
Eclesiología y sacramento en san Agustín
}

1. Cristo, la Iglesia y los sacramentos.

Se discuten y ponen hoy en interrogante aspectos teológicos que, luego al principio ya de su planteamiento, encontraron la auténtica dimensión y su perspectiva doctrinal adecuada. En esta línea de inconsistencia formal valorativa referentemente a la historia de los dogmas, no aceptamos apreciaciones y juicios apriorísticos formulados porque sí sobre otros tantos puntos y tesis fundamentales de la herencia teológica agustiniana . San Agustín es doctrinalmente abundante, complejo y de difícil sistematización. Víctima de la circunstancialidad y motivaciones concretas de sus escritos ${ }^{2}$, no es nada frecuente que las referencias particulares y detalles aislados de su exposición traduzcan y dibujen por sí solos el contorno total de su pensamiento. Ni siquiera un paciente trabajo de exégesis, de análisis detallado y confrontación amplia de textos lograría a veces definir del todo el alcance y densidad ideológica que el Santo de

1. Tesis de San Agustín sobre la gracia, el pecado original y sacramentos que, con relativa frecuencia, se critican porque no se las estudia directamente en los textos y a la luz del sistema teológico total agustiniano. Fenómeno éste que se inicia luego en tiempos del propio san Agustín. Sirva de ejemplo la siguiente observación de Vanneste: "A nuestro juicio -escribe-, si algún reproche debe hacerse al Concilio de Cartago, es el de no haber seguido a Agustín hasta el final. Precisamente porque los Padres del Concilio se mantuvieron en lo que podríamos llamar el estado preagustiniano de la cuestión, su anatema sobre el pecado original en sí $y$ en su afirmación fundamental no se encuentra apoyado por considerandos que respondan plenamente a las exigencias de la teología moderna... A pesar de no haber sabido situar el debate al nivel que Agustín habia apuntado, el canon 2 del Concilio de Cartago contiene un valor dogmático indiscutible, por lo menos para aquel que sabe descubrir su significación profunda, la que el obispo de Fipona ha sido el único en explicar perfectamente": C. VANNESTE, "El Decreto del Concilio de :Trento sobre el pecado original": Selecciones de Teología 29 (1969) 63.

2. Es una de las constantes, bastante generalizada, de la producción literaria de san Agustín, envuelto y complicado siempre en controversias y refutaciones de otras tantas posturas que atentaban contra el dogma y la vida interna de la Iglesia: pelagianos, donatistas, maniqueos, actitudes no rectas enfrentadas al cristianismo: cf., entre otros, G. BARDY, Saint Augustin. L'homme et l'oeuvre. Paris, 1946. 
Hipona atribuye a conceptos tan primarios y de tanta vigencia doctrinal como el de "Cuerpo de Cristo" ${ }^{\text {, }}$ pero con implicaciones en este caso inequívocas de cristología, de eclesiología y de sacramentaria.

Inicialmente, san Agustín tiene una visión dinámica y sugestiva, llena de interés humano, del hacer divino sobrenatural que regenera y justifica al hombre. Su antropologia es de signo afirmativo e integrativa de los diferentes elementos que constituyen y condicionan los rasgos efectivos del orden de la gracia. A nivel concreto de realidades que encarnan la dialéctica de la sobrenaturalización, Cristo, la Iglesia y los sacramentos describen la gráfica objetiva que interesa el acontecimiento visible y eficaz, personificador de la llamada a la sobrenaturalidad de la vida y apertura del hombre a la comunión con Dios y con los otros - los redimidos - mediante la gracia 4 . Cristo, la Iglesia y los sacramentos son para el Obispo de Hipona realidades implicadas, que se corresponden, aunque no reversibles en el proceso de la dialéctica de la salvación: Cristo, caput Ecclesiae y auctor sacramenti ${ }^{5}$; la Iglesia, corpus Christi, que alcanza su más intima esencia de societas sanctorum y su realización más profunda en el sacramentum (eucarístico) ${ }^{6}$; y, por último, los sacramentos, donde se representa y actualiza significativamente la unidad actuante que existe entre Cristo y la Iglesia.

Al hablar de la concepción sacramentaria de san Agustín resulta, en consecuencia, noco convincente desligar su modo de proceder explicativo de la soteriología, ya que la Iglesia-Madre, depositaria y administradora de los sacramentos, es el Cuerpo de Cristo-Cabeza, principio y referencia determinante de toda acción salvifica. Para el Obispo de Hipona, la doctrina sobre los sacramentos configura un

3. Se trata, sin duda, de uno de los pensamientos más fecundos y actuales de la doctrina agustiniana. Con la ventaja de que reúne ciertamente los factores y elementos más genuinos y cercanos a la problemática actual; cfr.: F. HOFFMANN, Der Kirchenbegriff des hl. Augustinus. Munich, 1933; L. GRABOWSKI, La Iglesia. Introducción a la teología de san Agustin. Madrid, 1965; T. VAN BAVEL, Recherches sur la christologie de saint Augustin. Fribourg, 1954; E. MERSCH, Le Corps Mystique du Christ2; II (Paris 1936).

4. Cf. E. MERCH, Le Corps Mystique, 84-86.

5. El segundo de los puntos es fundamental y de los más significados en su controversia antidonatista: cfr. B. QUINOT, Introduction générale aux Traités Anti-donatistes: III. Contra litteras Petiliani libri tres (Paris 1967) 82-84.

6. "San Agustín, es cierto, ensalza con reiteración la eucaristía como el sacramento de la unidad, incluyendo en el ser eucarístico el cuerpo místico de Cristo. El totus Christus, Cabeza y miembros, es el contenido -y contenido integral- de la eucaristía": S. FOLGADO FLOREZ, "La eucaristía "sacramentum unitatis" en la eclesiología de san Agustín": La Ciudad de Dios 167 (1964) 609. 
capítulo destacado del todo teológico que interfiere la cristologia y la eclesiología. No son -los sacramentos- sin más el signum sacrum, cuya entidad se agota en el propio concepto. También se integran plenamente en la dinámica de la salvación y tienen su equivalencia, valor y alcance de acontecimiento salvífico. El sacramentum transciende entonces la noción limitativa de signo para expresar, dentro del esquema doctrinal agustiniano, otros aspectos de mayor amplitud temática a lo largo de sus obras relacionados con la realización de la vida de la Iglesia .

Gracias a su visión vitalista de la historia de la salvación, san Agustín encuentra siempre la clave conciliadora de posturas encontradas frente al sacramento del bautismo ${ }^{8}$, en la noción sintética -quae facit caritas ${ }^{9}$ - de la unidad. La unidad católica es la primera de las propiedades del Cuerpo de Cristo; la más fundamental y especifica. La que sirve de sostén y objetiviza la línea conceptual teológica de la mediación maternal aplicada a la Iglesia, sujeto eclesiológico único de las acciones sacramentales en validez de eficacia regenarativa.

En contraste con el cisma y negadores del dogma, san Agustín es la apelación personificada a la unidad de la Iglesia. Cada momento histórico de su vida - actitud-va determinando el signo de su obra - teología - como llamada persistente, transida de interés pastoral y llena de convicción, a la unitas "en un solo cuerpo". La unidad en su doble vertiente - de indivisión estructural, interna, y de unión caritativa de los fieles- reproduce el misterio mismo de la Iglesia, considerada como institución salvífica de la humanidad tendente a la plenitudo Christi. "San Agustín -escribiamos hace tiempo- describe con rasgos inequivocos el proceso unificador e integrante mediante el cual se completa la unidad del Cuerpo místico.

7. No aceptamos, en consecuencia, la observación de $R$. SCHUULTE cuando escribe: "que Agustín... introdujo de hecho una estrechez de perspectivas". en la concepción teológica sacramentaria: R. SCHULTE, "Los sacramentos de la Iglesia como desmembración del sacramento radical": Mysterium Salutis IV/ 2 (1975) 110. Schulte, creemos, no llega a comprender el significado y radical amplitud de la soteriología agustiniana.

8. Y. M.-J. CONGAR, Introduction générale aux Traités Antidanotistes, I (Paris 1963) 48-50.

9. In Ioannis evangelium tr. 27,6. “...il est vrai que, grâce peut-être a savision vitaliste de l'oeuvre du salut, unité et distincion se concilient chez lui, comme nous le verrons, dans la notion synthétisante de charité. Mais le principal, c'est l'unité; ce n'est que dans un second mouvement dialectique que toutes les précisions, voire les corrections, nécessaires sont apportés, que éclairent et finalement enrichissent l'idée d'unité": P. BORGOMEO, L' Église de ce temps dans la prédication de saint Augustin (Paris 1972) 226-227. 
Toda su exposición constituye una referencia continua a ese factor primario de su teología que notifica el Cuerpo de Cristo, cuya correspondencia unitaria, previvencial y continuada, expresa la caridad a. fin de que podamos ser miembros suyos - de Cristo ${ }^{10}$-. El misterio de la plenitud de Cristo descubre toda su radicalidad y actuación cuando se relaciona con otros misterios en el conjunto orgánico y sobrenatural de la revelación, en donde la eucaristía destaca como elemento primordial, originario, que culmina la Iglesia. La identificación perfecta se cumple de hecho en el sacramento de la unidad mediante una unión real, íntima y substancial, de los miembros con su Cabeza formando un solo Cristo" "11.

La unidad católica de la Iglesia, requisito ineludible de su maternidad mediadora, define el contexto ideológico apto que caracteriza y da relieve, configura la concepción agustiniana de los sacramentos, bautismo, penitencia y eucaristía expresamente, sobre un plano de virtualidad efectiva derivante de Cristo-Cabeza, que se sitúa al origen del acontecer salvífico sacramental. Destaca a este respecto su teoría de la catolicidad dinámica e integradora de la Iglesia una, tal como la propone y significa en su larga controversia con el donatismo ${ }^{12}$. Si algo distingue y confiere carácter de especificación a la eclesiología de san Agustin, para nosotros, es la idea católica connotativa de la unidad ${ }^{13}$. Es, asimismo, el denominador común, la fórmula y principio generalizado, que sustenta la sistematización doctrinal y sugiere las conexiones reales de la Iglesia con otros contenidos primarios de la revelación, siendo aspectos particulares inherentes, que explicitan la funcionabilidad eclesiológica del concepto en referencia clara a los siguientes enunciados: la eucaristia, sacramentum unitatis; Pedro, símbolo de la unidad; relaciones de

10. Cf., por ejemplo, Enarrationes in Ps. 30,1,3: "Nam sine illo, nos nihil; in illo autem, ipse Christus et nos. Quare? Quia totus Christus caput et corpus, Caput ille salvator corporis; quia iam ascendit in caelum; corpus autem Ecclesia, quae laborat in terra. Hoc autem corpus nisi connexione caritatis adhaereret capiti suo, ut unus fieret ex capite et corpore, non de caelo quemdam persecutorem corripiens diceret: Saule, Saule, quid me persequeris? (Hech 9, 4)... Caput pro membris clamabat, et membra in se caput transfigurabat". Cf. P. PIOLANTI, "Il mistero del "Cristo totale" in S. Agostino": Augustinus Magister, III (Paris 1954) 453-455.

11. Cf. S. FOLGADO FLOREZ, La eucaristia, 627-628.

12. El tema de la catolicidad de la Iglesia es uno de los motivos más constantes y reiterados y que con mayor profusión y variedad de fórmulas expresa la eclesiología agustiniana. $\mathrm{Y}$ así, por ejemplo, hablará san Agustín del "universum corpus" (Serm. 96,9), del "universus Christus" (De diversis quaestionibus, 83, 69, 10), de la Iglesia "universa in caelo et in terra" (Enchiridion 15, 56).

13. Cf. S. FOLGADO FLOREZ, Dinamismo católico de la Iglesia en san Agustin. El Escorial, 1977. 
reversibilidad equivalente - a nivel de Iglesia- entre la caritas y la unitas; unidad y apostolicidad; unidad y presencia del Espíritu Santo; unidad católica y eficacia, virtud y acción santificante de los sacramentos ${ }^{14}$.

En. la unidad católica, connotación cualitativa además de númerica de la Iglesia, san Agustín ve el clima indispensable para toda la vida cristiana. Porque, en definitiva, se trata de la unidad misma de Cristo, es decir, de la unidad de su Cuerpo in plenitudine Ecclesiae. Unidad garantizada, a su vez, por la presencia vitalizadora y unificativa del Espíritu Santo ${ }^{15}$, alimentada por un mismo pan, expresada por una fe única y hecha testimonio por la práctica y vivencia de la caridad ${ }^{16}$. $\mathrm{X}$ como premisa mayor inspiradora de los consiguientes enunciados eclesiológicos, presupone una cristología de perfiles totales; sistema teológico que, a la luz del Evangelio y desde una perspectiva dinámica, considera a Cristo autor de la gracia y Cabeza que influye y comunica la vida sobrenatural a su Cuerpo, la Iglesia. Es obvio, por lo mismo, que al desarrollar su teoría sobre los sacramentos, por encima y más allá de la atribución humana de carácter constitutivo propuesta por los donatistas ${ }^{17}$, san Agustín supere el ámbito ministerial y busque las razones auténticas de su eficacia y virtud santificadora en referencia a Cristo y a la Iglesia ${ }^{18}$.

14. Cf. E. LAMIRANDE, La situation eclésiologique des donatistes d'après saint Augustin. (Ottawa 1972) 130.

15. Cf. H. MUHLEN, Una mystica persona. La Chiesa come il mistero dello Spirito Santo in Cristo e nei cristiani; una persona in molte persone. Roma, 1968.

16. Cf. D. FRANSES, "Augustinus en de eenheid der kerk": Miscellanea Augustiniana, (Rotterdam 1930) 137-150; L. ALFONSI, "Unità cattolica e romana nel Psalmus contra partem Donati di sant'Agostino": Studi Romani 6 (1958) 407-412. Es también la doctrina de san Cipriano: "Ecclesia una est quae in multitudinem latius incremento fecunditatis extenditur...": De catholicae Ecclesiae unitate 5.

17. Según san Agustín, "les Donatistes y mettaient toute leur théologie d'une véritable transmission de qualité spirituelle par celui qui donnait le bap_ tême ou l'ordre: chacun donne ce qu'il a lui-même; ainsi le ministre consécrateur était-il, selon eux, vraiment générateur et père": Y. M.- J. CONGAR, Introduction générale, 102-103. Lo que sí resulta cierto es, que al insistir con preferencia y a nivel de principio sobre las condiciones personales del ministro dentro de la Iglesia, limitaban de manera sorprendente la acción de Cristo en la obra regenerativa.

18. Las obras principales de san Agustín sobre el donatismo y donde expone su teoría, uno de los logros teológicos-doctrinales más caracterizados de todos los tiempos, son: Psalmus contra partem Donati; Contra Epistolam Parmeniani libri tres;De baptismo contra donatistas libri septem; Contra litteras Petiliani libri tres; De unitate Ecclesiae liber unus; Contra Cresconium grammaticum partis Donati libri quatuor; De unico baptismo contra Petilianum liber unus; Breviculus collationis cum donatistis; Ad donatistas post collationem; Sermo ad 
La doctrina sacramentaria del Obispo africano pretende todavía explicar el modo diríamos concreto de realizarse la incorporación eclesial del hombre a Cristo. Modo que resalta de manera especialísima en el bautismo, sacramento de la concorporación al Cristo mistico, y en la eucaristía, sacramentum unitatis y factor determinante de la "congregatio ecclesialis" en comunión real, efectiva y transustancializada de corazones ${ }^{19}$. El bautismo regenera al hombre porque lo articula, vitalmente, al cuerpo comunitario y social de la Iglesia. De hecho el valor unitario del bautismo, como factor sacramental de la unidad eclesial, reside sin duda en que todos, los regenerados por el agua, participan del propio Espíritu de Cristo en orden a la constitución de un solo Cuerpo ${ }^{20}$. También la eucaristía se totaliza como sacramentum, porque allí se verifica y sella la unidad del Hijo de Dios con todos los hombres, vitalizando el sentido orgánico (?) del cor unum y anima una de la espiritualidad agustiniana ${ }^{21}$. "Indudablemente el aspecto estructural de la Iglesia dice orden a la unidad interior y mística, a la unión espiritual de corazones, no sólo de sentimientos, sino verdadera y participada. La eucaristía, sacramento de amor que "hace la Iglesia", prefigura plenamente y realiza la unidad de Cristo, Cabeza y miembros, en la caridad" ${ }^{22}$.

En esta línea de proyección eclesial, de Cuerpo místico y efectividad cristológica de los sacramentos, san Agustín razona además, desde la teología, el qué específico del signum sacrum sobre el análisis de la consecratio o unción ritual que, según la praxis prefiguradora del antiguo Isräel, establecía un orden de dignidádes -dedicaciones del lado de lo funcional-z y habilitaba para el cumplimiento

Caesariensis Ecclesiae plebem; De gestis cum Emerito liber unus; Contra Gaudentium donatistarum episcopum libri duo.

19. Los donatistas cifraban la pertenencia a la Iglesia en la posesión del signo sacramental. Para san Agustín, sin embargo, una cosa es la realidad sacramental externa y otra, diversa, la causalidad sacramental; de nada sirve el signo si no tiene el espíritu de Cristo a que hace referencia: espíritu de comunión expresado en la unidad de la Iglesia, Cuerpo de Cristo.

20. Es, por otra parte, doctrina clara de san Pablo; cf., por ejemplo, 1 Cor $12,13$.

21. Lo que no es obstáculo para que cada miembro mantenga su propia independencia y funcionabilidad: "Quomodo singillatim membra formata sunt omnia, singillatim habent opera sua, et tamen in unitate corporis vivunt; manus facit quod oculus non facit, auris id valet quod nec oculus nec manus valet; omnia tamen in unitate operantur, et manus et oculus et auris diversa faciunt, nec sibi adversantur; sic et in Christi corpore singuli homines, tamquam membra singula donis gaudent, quia ille qui elegit populum in haereditatem sibi, finxit singillatim corda eorum": Enarrationes in Ps. 32,2,21.

22. Cf. S. FOLGADO FLOREZ, La eucaristía, 628. También el Vaticano II: "Por el sacramento del pan eucarístico se representa y reproduce la unidad de los fieles, que forman un solo Cuerpo de Cristo": Const. dogm. sobre la Iglesia Lumen Gentium 3. 
de un cometido perfectamente tipificado ${ }^{23}$. La unción equivalía y equivale a una caracterización personal, a la marca y sello, distintivo vocacional a lo divino. Y așí subraya el Obispo de Hipona la consecratio como el título ontológico, querido por Dios, que "cristifica" al hombre mediante el sacramento y lo introduce, al amparo de la unidad mística correspondiente a un mismo Cuerpo, en la dinámica eclesial de la salvación impuesta por Cristo-Cabeza, el ungido por antonomasia con el sello y virtualidad del Espíritu.

Para san Agustín resulta axiomático que dicha unidad mística articulada en Iglesia depende, originariamente, de la propia unción de Cristo, que llega, a través de los sacramentos, hasta nosotros, incorporándonos a $\mathrm{El}$ y haciéndonos miembros suyos. La unción, es decir, la "cristificación" de signo sacramental, significa la elevación ontológica, entitativa, del hombre al orden sobrenatural realizada eclesialmente. De donde se infiere que "todos somos Cuerpo de Cristo, porque somos ungidos, y todos estamos en El, siendo Cristo y de Cristo, porque de alguna manera el totus Christus es Cabeza y Cuerpo. Esta unción nos perfeccionará espiritualmente en aquella vida que se nos promete... Ahora somos ungidos en el sacramento, y por: el mismo sacramento se prefigura algo de lo que hemos de ser" ${ }^{24}$. En consecuencia, el carácter consecratorio o uncial del sacramento se verifica sobre una base cristológica - puesto que Cristo es el sacramento original-que sólo en la Iglesia y por la Iglesia -principio sacramental a su vez- prolonga y actúa su virtud unitiva. Scheeben, el gran teólogo alemán que supo captar, como nadie, el significado y densidad de las enseñanzas patrísticas, acentúa, por otra parte, el aspecto dinámico de la "cristificación" desde la perspectiva de lo esponsalicio sacramental. "El hombre - escribe - ha de unirse en la fe con su Esposo divino, y éste quiere sellar, como con un anillo nupcial, su alianza con el hombre en el bautismo. $Y$ ambas cosas se hacen tan sólo para fundir en la eucaristía... al hombre y al Hombre-Dios en una sola carne y fecundar al hombre de modo más perfecto con la virtud de la gracia, propia de la Cabeza. De modo que cada alma, al entrar en la Iglesia, se convierta en esposa verdadera del Hijo de Dios" ${ }^{25}$.

23. "Et solus tunc ungebatur rex, et sacerdos: duae istae illo tempore unctae personae. In duabus personis praefigurabatur futurus unus rex et sacerdos, utroque munere unus Christus, et ideo Christus a chrismate. Non solum autem caput nostrum unctum est, sed et corpus eius nos ipsi": Enarrationes in Ps. 26, $2,2$.

24. Enarrationes in Ps. $26,2,2$. 573.

25. Cf. M. J. SCHEEBEN, Los misterios del cristianismo (Barcelona 1960) 
La conclusión reproduce con fidelidad el sentir agustiniano sobre el alcance y pertenencia activa, maternal inherente a lo esponsalicio, del fiel cristiano en la Iglesia, Esposa y Cuerpo de Cristo, dotada de un dinamismo católico fundamental expresado y hecho presencia actuante, recapituladora e integrativa socialmente, en los sacramentos y a causa de los sacramentos ${ }^{26}$.

2. Cristo, Cabeza de la Iglesia, autor de los sacramentos.

El vigoroso y reiterado acento con que san Agustín destaca, siempre en un primer plano, la actividad salvífica de Cristo le permite, facilitando sin duda el proceso teológico, la recta formulación de la dinámica soteriológica, donde la Iglesia aparece también como principio de vida sobrenatural pero subordinado. Cristo, sacramento del Padre, es el origen de la gracia, el Mediador, el orbis emptor del que emerge la communio ecclesialis, su heredad ${ }^{27}$, cuya virtud "cristificadora" adquiere, asimismo, vigencia y formalidad práctica de razón actuante per verbum et sacramenta ${ }^{28}$, que son realizaciones salvíficas de la propia Iglesia y una de las posibilidades aquí más profundas del encuentro personal con Dios.

La Iglesia, estructurada en función de una sacramentalidad específica ${ }^{29}$, imprime contextura social a la acción única de Cristo, la presencializa a través de la historia y sirve de referencia obligada a los sacramentos de la Nueva Ley. La virtualidad de los mismos, su eficacia e incluso su forma de ser representativa apuntan al dato de que son expresiones diríamos vitalizantes, instrumento de la Iglesia, para hacernos a todos, bajo esa realización significativa de cosas, símbolos, gestos y palabras, participantes de la realidad invisible - la gracia y donación del Espíritu de Cristo, que nos concorpora de este modo a su Cuerpo ${ }^{30}$. "No hay otro sacramento de Dios (Dei

26. Enarrationes in Ps. 32,2,21; cf. asimismo A. ALCALA GALVE, La Iglesia, misterio $y$ misión (Madrid 1963) 376.

27. Contra litt. Petiliani II, 8,20.

28. "...Spiritualiter ergo nascimur, et in spiritu nascimur verbo et sacramento": In Iohannis evangelium tr. 12,5.

29. Cf. O. SEMMELROTH, "La Iglesia como sacramento de la salvación": Mysterium Salutis IV/1 (Madrid 1973) 321-329.

30. Se llaman sacramentos precisamente "quia in eis aliud videtur, aliud intelligitur. Quod videtur speciem habet corporalem, quod intelligitur fructum habet spiritualem" (Sérm. 272,3). "Invisibili gratia (sanctificatur homo) per Spiritum Sanctum, ubi est totus fructus etiam visibilium sacramentorum. Nam sine ista sanctificatione invisibilis gratia sacramenta visibilia quid prossunt" (Quaestiones in Heptat. 3,84). "Aqua sacramenti visibilis est... abluit corpus, et significat quod fit in anima" (In Ep. Iohannis ad Parthos 6,11). 
mysterium) -escribe san Agustín- que el Cristo" ${ }^{31}$. Y no hay otro sacramento de Cristo que la Iglesia. Cristo sacramento de Dios, la Iglesia sacramento de Cristo: "Estos son los dos sacramentos radicales, Ursakrament; éstos son el misterio. Fuente de los otros siete sacramentos" 32 .

En este punto el misterio de Cristo, misterio de redención, de la Iglesia, de los sacramentos, consigue el máximo de expresibilidad y amplitud por su proyección "capital", de gracia, en la historia de la salvación. Tres son, según san Agustín, los matices o dimensiones que la Sagrada Escritura predica de Cristo: la dimensión deífica, en cuanto Dios igual al Padre y coeterno con El antes de la encarnación; la dimensión en cuanto Dios-Hombre y Hombre-Dios a la vez, mediador y Cabeza de la Iglesia; y, finalmente, la dimensión mística - su tercer estado- en cuanto Cristo integro; completo o total in plenïtudine Ecclesiae, que es Cabeza y Cuerpo; y en la plenitud de esa perfección orgánica -secundum plenitudinem perfecti cuiusdám viri- somos nosotros miembros de este hombre único y perfecto mediante la gracia que deriva de Cristo-Cabeza ${ }^{33}$. La dimensión eclesial de la encarnación es capítulo clave de la soteriología agustiniana ${ }^{34}$. Desde siempre Cristo está destinado a ser Cabeza, a difundir la perfección de su gracia sobre nosotros y a comunicar la vida sobrenatural a los hombres. De ahí que la recapitulación en Cristo, plenitud de la Iglesia, comporte dos momentos integrativos fundamentales: constitución de la Cabeza e incorporación de los miembros ${ }^{35}$.

Frente a Cristo, sacramento personal de Dios, la Iglesia es ya sacramento derivado, obra suya y dependiente de su iniciativa. Porque si es cierto que para san Agustín la Iglesia es la plenitudo Chris$t i$, la apelación tiene, sin embargo, sentido de atribución restringi-

31. Ep. 187,34: "Non est aliud Dei mysterium nisi Christus".

32. Cf. A. ALCALA GALVE, La Iglesia, 152.

33. Serm. 341, 1: "Dominus noster Iesus Christus quantum animadvertere potuimus paginas sanctas, tribus modis intelligitur et nominatur, quando praedicatur... Primus modus est, secundum Deum et divinitatem illam Patri icoaequalem atque coaeternam ante assumptionem carnis. Alter modus est, cum assumpta carne iam idem Deus qui homo et idem homo qui Deus... mediator et caput Ecclesiae. Tertius modus est quodam modo totus Christus in plenitudine Ecclesiae, id est caput et corpus, secundum plenitudinem perfecti cuiusdam viri, in quo viro singuli membra sumus".

34. Cf. J. A. GOENAGA, La humanidad de Cristo, figura de la Iglesia (Ma. drid 1963) 25-52, donde analiza las distintas fórmulas de la "encarnación eclesial". que san Agustín propone en las Enarrationes in Psalmos.

35. Sobre este punto -teología por excelencia del Cuerpo místico- la doctrina de san Agustin es abundante y profunda, definitiva. 
da al Cuerpo, es decir, a lo eclesial, en cuyo ámbito actúa El como Cabeza. Sólo a partir de Cristo y con Cristo, y por participar en el ser, virtualidad y Espíritu de Cristo puede la Iglesia ser sacramento radical, continuadora de su acción redentiva, y que está, por eso mismo, implicada entitativa y funcionalmente en el quehacer (sacramental) de ir completando a Cristo. "El Dios de nuestro Señor Jesucristo ha realizado, mediante este Hijo suyo, la salvación de los hombres y del mundo de tal forma que la realización actual es la Iglesia. $\mathrm{Y}$ esta Iglesia realiza su ser y el encargo implicado en él viviendo y derramando en comunión salvadora - como participación suya en este único acto salvífico del Dios Padre- esta misma salvación, la vida que Dios ha otorgado, y lo hace junto con su Cabeza, mediante ella y como su $\sigma \tilde{\omega} \mu \alpha$ y $\pi \lambda \dot{\eta} p(1) \mu \alpha{ }^{36}$.

Precisamente la connotación de plenitud eclesial que recorre el pensamiento agustiniano, nos obliga a contemplar el misterio de la Iglesia, Pueblo de Dios y Cuerpo de Cristo, en la comunión de todos sus miembros en cuanto integrantes de un organismo sobrenatural, con el encargo histórico de cumplir una tarea de redención. Una y mil veces repite san Agustín que Cristo y la Iglesia son una misma cosa, un solo hombre perfecto, un solo hombre en su plenitud, un solo Cristo ${ }^{37}$, que la Iglesia constituye con Cristo una quaedam persona - unidad atributiva de propiedades místicamente articulada-; y que ambos encarnan el misterio grande (in sacramento to magno) de ser dos en una carne, duo in voce una -principio también único de funcionabilidad salvífica ${ }^{38}$. Por supuesto que trasciende nuestro propósito el recoger aquí, siquiera brevemente, la profusión de detalles y de fórmulas con que glorifica la unidad y correspondencia existentes entre Cristo y la Iglesia, el Esposo y la Esposa, la Cabeza y los miembros.

Al interpretar, pues, el sentir teológico agustiniano sobre los sacramentos, no es viable metodológicamente el estudio que pres-

36. Cf. R. SCHULTE, Los sacramentos de la Iglesia, 74.

37. Cf., por ejemplo, Enarrationes in Ps. 26,2; In Iohannis evangelium tr. $21,8-9$.

38. Enarrationes in Ps. 30,2,1, $\mathrm{Y}$ con mayor expresividad resume todavía su pensamiento en el Serm. 2,1, de la exposición de este mismo salmo: "Commendaveram Caritati Vestrae, cum primas partes huius psalmi exponerem, quod Christus loquatur; et quomodo sit accipiendum Christus totus cum capite et corpore, non tacueram; testimoniis etiam Scripturarum, quarum mihi videtur, satis idoneis luculintisque firmaveram; ita ut omnino dubitari non posset Christus esse caput et corpus, sponsum et sponsam, Filium et Dei Ecclesiam, Filium Dei factum filium hominis propter nos, ut flios hominum faceret filios Dei ; atque - ita essent duo in carne una in sacramento magno, qui agnoscuntur in Prophetis duo in voce una". 
cinda de su teoría general relacionada con el Cuerpo místico, porque de hecho es ella la que marca el orden de primacias a establecer en la escala de causalidades y de mediaciones: al origen, Cristo; y como realizadora ulterior de lo ya realizado antes, la Iglesia. Existe una constante afirmativa, a lo largo de sus obras, que sitúa a Cristo a la base de toda acción salvífica como fuente original, primera y determinativa, de toda eficacia regeneradora. Siempre es Cristo el que "sacrifica y el que sacramentaliza, el que bautiza y absuelve, perdona los pecados con la Iglesia" ${ }^{39}$. En esta precisa dirección, la postura teológica agustiniana consigue valor definitivo de tesis, complaciéndose el Santo en subrayar que, desde la perspectiva del Dios-Hombre, "Cristo es el que bautiza" y que a El sólo corresponde la potestad de bautizar ${ }^{40}$. Lo que no obsta para que la Iglesia esté institucionalmente ordenada a la regeneración del hombre, a darle una dimensión y destino nuevos a tono con el existir sobrenatural que se le participa. La Iglesia, además de Cuerpo de Cristo, es también su Esposa, el adiutorium simile sibi, la segunda Eva que, fecundada por la virtud del Espíritu, asume el cometido de alumbrar para Dios hijos de la gracia ${ }^{41}$. Pensamiento este muy típico de san Agustín, de grandes posibilidades teológicas todavía hoy, que explica la fecundidad de la Iglesia como organismo y realidad mistica, tendente a la plenitud católica del todo, en función de una maternidad-virgen característica ${ }^{42}$.

Es, sin embargo, a través de la controversia antidonatista, cuando San Agustín discute las posturas contrapuestas, razona los principios dogmáticos e infiere con exactitud el alcance teológico definitivo de su teoria sacramentaria. Teoría que si surge condicionada al amparo de las discusiones y posturas antagónicas sobre el bautismo, rebasa luego los límites particularizados de la polémica para ser ampliable a los demás sacramentos en el constitutivo formal de sus elementos definitorios.

Cristo, verdadero sujeto de las acciones sacramentales, es el auctor baptismi, quien bautiza en el Espíritu Santo según lo prometi-

39. Cf. A. ALCALA GALVE, La Iglesia, 263.

40. De baptismo V, 12,14; In Iohannis evangelium $t r$. 5,18, comentando las palabras de san Juan 4,2 ("pues no bautizaba El, sino sus discipulos") escribe: "Ipse, et non ipse, potestate; illi, ministerio; servitutem ad baptizandum illi admovebant, potestate baptizandi in Christo permanebat... Quos autem baptizabit Iudas, Christus baptizabit. Sic ergo quos baptizavit ebriosus, quos baptizavit homicida, quos baptizavit adulter, si baptismus Christi erat, Christus baptizavit".

41. Cf. M. J. SCHEEBEN, Los misterios del cristianismo, 571.

42. Cf. S. FOLGADO FLOREZ, "San Agustín y su eclesiología mariana": La Ciudad de Dios 178-179 (1963) . 445-462. 
do ${ }^{43}$, y el que confiere al sacramento la dimensión salvífica inherente a su propio dinamismo santificador. Hoy como ayer, y siempre, será la presencia conformadora del Resucitado en el "sacramento del Dios vivo": (sacramentum Dei vivi) el título válido de la proclamación cristiana: de que somos efectivamente los "bautizados de Cristo"; cuius est baptisma verum. El bautismo de la regeneración, el bautismo cristiano y de la Iglesia, es el "bautismo del Cristo viviente" "44. A causa de ello el Obispo de Hipona siente la urgencia de reconocer la validez del sacramento administrado por los herejes, cismáticos y pecadores ${ }^{45}$. Aunque la razón profunda, axiomática para él, reside en que Cristo es el solo y supremo Pontífice, el único que puede realmente cumplir una función sacerdotal frente a Dios ${ }^{46}$. Por lo que, a nivel interpretativo, resulta difícil no tener en cuenta la línea dominante de su cristología que se desarrolla y esquematiza sobre el concepto de Cristo-Mediador ${ }^{47}$.

Los donatistas, representantes genuinos de un exacerbado nacionalismo religioso, desfiguran la naturaleza intima de los sacramentos y de la Iglesia toto orbe diffusa, una y católica, al desvalorizar desde dentro el cometido primordial de Cristo atribuyéndose a sí mismos la misión de comunicar la gracia y de santificar a los hombres. Convierten la realidad sobrenatural y dogmática del sacramento en cuestión de antropologia indirecta que marginaba incluso lo personal del propio interesado. Toda la razón actuante del signum sacrum, de su eficacia regenerativa y de concorporación a la Iglesia, la hacian depender de las condiciones y aptitudes del ministro. Relegaban asi a un segundo plano la iniciativa divina y el bautismo no era el sacramento de Cristo para los hombres, sino el sacramento del actor ministerial donatista para los donatistas ${ }^{48}$.

43. Contra litt. Petiliani II, 2,5; II, 24,47: "Baptismus in nomine Patris et Filii et Spiritus Sancti Christum habet auctorem".

44. Contra litt. Petiliani II, 7,15; II, 7,16: “...Sicut ergo a viro baptizatur qui vivi Christi baptismo induitur".

45. Contra litt. Petiliani II, 107,247: "Sic approbamus in haereticis baptismum non haereticorum sed Christi, sicut in fornicatoribus, immundis, luxuriosis, idololatris, veneficis, inimicitiarum retentoribus, contentiosis, aemulis, animosis, dissensionum studiosis, invidis, ebriosis, comesatoribus et his similibus appro bamus baptismum non eorum sed Christi".

46. Contra litt. Petiliani II, 105,241.

47. Si la posición de los donatistas fuese cierta, significaría lógicamente que Cristo no es el único Mediador. Desde la perspectiva del real y positiva de Cristo sobre la acción externa sacramental, san Agustín resuelve el problema dogmático y teológico que plantea la administración de los sacramentos por ministros indignos.

48. Sobre el donatismo la obra fundamental sigue siendo la de P. MONCEAUX, Histoire littéraire de l'Afrique chrétienne depuis les origines jusqu'd 
San Agustín pone todo su empeño y capacidad dialéctica en mostrar que, si bien el ministro le proporciona el ministerio, la fuente de donde brota la santidad participada a los sacramentos ${ }^{43}$, Cristo, personaliza el poder, fundamento de la unidad de la Iglesia e intransferible por otra parte, de bautizar en el agua y en el Espíritu ${ }^{50}$. El es el origen; la raíz y la cabeza del orden de la gracia; el principio, el desarrollo y la culminación del quehacer espiritual cristiano ${ }^{51}$. Cristo purifica e incorpora a su Cuerpo en el bautismo, enriquece con una fortaleza especial del Espíritu Santo y vincula a los fieles más estrechamente a la "societas sanctorum" en la confirmación, perdona los pecados y reconcilia con la Iglesia en el sacramento de la penitencia, incrementa la vida espiritual y presencializa, significándola, la unidad de los creyentes en la eucaristia ${ }^{52}$. Dios está actuante en los sacramentos y en sus palabras - sacramentis et verbis suis-, sin que la situación moral del ministro, estado de gracia o de culpa, comprometa por ello la razón originaria del signo sacramental, su validez y eficacia ${ }^{53}$.

Por el contrario, las actitudes afines a la mentalidad donatista, que propugnan sustitutivos mediatizadores de la santidad esencial y

l'invasion arabe. Paris 1901-1923; 7 volúmenes. Interesan en especial vol. IV: Le donatisme (1812); vol. VI: Littérature donatiste au temps de saint Augustin (1922); vol. VII: Saint Augustin et le donatisme (1923). Desde un punto de vista histórico doctrinal: G. BAREILLE, "Donatisme": Dictionnaire Théol. Cath. IV/ 2 (1911) cols. 1701-1728; A. PINCHERLE, "L'ecclesiologia nella controversia donatista": Ricerche Religiose 1 (1925) 25-55; G. NICOTRA, "Dottrina sacramentaria ed ecclesiologica presso i donatisti": La Scuola Cattolica 70 (1942) 141-147; 227-236; 303; 314; E. PRINA, La controversia donatista alla luce della dottrina del Corpo mistico di Gesú Cristo nelle opere antidonatistiche di S. Agostino. Roma, 1942; G. G. VILLIS, Saint Augustine and the Donatist Controversy. London, 1950; E. LAMIRANDE, La situation ecclésilogique des donatistes d'après saint Augustin. Ottawa, 1972; cf. también: J. P. BRISSON, Autonomisme et christianisme dans l'Afrique romaine, de Septime Sévère à l'invasion vandale. Paris, 1958.

49. "Nolite ex hominum moribus et factis divina sacramenta pensare. Illa enim per eum sancta sunt cuius sunt": Contra litt. Petiliani II, 37,88.

50. In Iohannis evangelium tr, 6, 6-7: "Per hanc enim potestatem, quam Christus solus sibi tenuit, et in neminem ministrorum transfudit, quamvis per ministros suos baptizare dignatus est, per hanc stat unitas Ecclesiae...". Quid ergo per columbam didicit (el Bautista), ne mendax postea inveniatur..., nisi quamdam proprietatem in Christo talem futurat, ut quamvis multi ministri baptizaturi essent, sive iusti; sive iniusti, non tribueretur sanctitas baptismi, nisi illi super quem descendit columba...? Petrus baptizet hic est qui baptizat; Paulus baptizet, hic est qui baptizat; Iudas baptizet, hic est qui baptizat".

51. "Origo mea Christus est, radix mea Christus est, caput meum Christus est": Contra litt. Petiliani II, 3,6.

52. Cf. VATICANO II, Const. dogm. sobre la Iglesia Lumen Gentium 11.

53. "Deus adest sacramentis et verbis suis, per qualeslibet administrentur, et sacramenta Dei ubique recta sunt": De baptismo V, 20,27. 
original de Dios, destruyen directamente la unidad y mediación de la Iglesia, con detrimento de las relaciones vitales de los cristianos entre sí, a la vez que desvirtúan la capitalidad de Cristo y vacian en la práctica de significado el misterio mismo de la redención. Ni siquiera queda a salvo la unidad del bautismo, cuando de hecho se relativiza su acción santificadora y se anula lógicamente, al menos a nivel de formulación, su precisa formalidad de acontecimiento salvífico. Porque, "si la potestad de santificar con el bautismo se transfiere del Señor al ministro, habría tantos bautismos como ministros y no quedaría en pie la unidad del bautismo" ${ }^{54}$.

La argumentación antidonatista de san Agustín reitera de continuo como punto de apoyo el tema de la unidad que rompe la herejia en todas sus dimensiones, de acuerdo con esa concepción suya eclesiológica y sacramentaria transida de equívocos. Pero que no se crea recibir el Espiritu Santo el que está separado de la unidad de los miembros ${ }^{55}$. Destruir la unitas Ecclesiae, romper a Cristo por dentro y atribuirse prerrogativas de mediación de la gracia que no le competen, constituye el máximo delito del cisma, cuyos presupuestos atentan sin paliativos contra la caridad, expresión la más significada del Espiritu que vivifica y configura el contorno orgánico de la societas por la que, en el bautismo, nos hacemos Cuerpo del mismo Hijo de Dios ${ }^{56}$. Al Espiritu Santo corresponde efectivamente la función vivificadora $\mathrm{y}$, al mismo tiempo, unificativa de unos miembros con otros articulados en un solo Cristo ${ }^{57}$. "La unidad social de la Iglesia de Dios, fuera de la cual no se da el perdón de los pecados, es como la obra propia del Espíritu Santo, realizada ciertamente con la colaboración del Padre y del Hijo, porque el Espíritu Santo es, en cierto modo, la comunión del Padre y del Hijo..." ${ }^{58}$.

A la luz y sobre la base de la función unificativa del Espíritu, san Agustin profundiza el misterio eclesial desde una perspectiva

54. In Iohannis evangelium tr. 6,6.

55. In Iohannis evangelium $t r$. 32,7: "In hac Ecclesia qui non est, nec modo accipit Spiritum Sanctum. Praecisus enim et divisus ab unitate membrorum, quae unitas linguis omnium loquitur, renunciet sibi: non habet. Nam si habét, det signum quod tunc dabitur... Loquatur omnibus linguis. Respondet mihi: Quid enim, tu loqueris omnibus linguis? Loquor plane, qua omnis lingua mea est, id est, eius corporis cuius membrum sum... Unitas enim membrorum caritate concordat: et ipsa unitas loquitur, quomodo tunc unus homo loquebatur". Y más claramente todavía: "Norunt fideles corpus Christi, si corpus Christi esse non negligant. Fiant corpus Christi, si volunt vivere de Spiritu Christi. De Spiritu Christi non vivit, nisi corpus Christi": In Iohannis evangelium tr. 26,13.

56. Serm. 71,28.

57. Serm. 142,11: “... Omnibus membris sanitatem dedit, compaginem dedit, unitatem dedit. Spiritu omnia pariter vivificavit, univit".

58. Serm. 71,33 . 
trinitaria. En la intimidad de la vida divina lo proprium del Espiritu Santo es la societas, el amor personal, el ser vínculo de infinita fuerza y cohesión, que enlaza al Padre y al Hijo protagonizando su unión $\mathrm{y}$ acabada unidad. $\mathrm{Y}$ según el principio clásico de teología de que la Trinidad económica se corresponde con la Trinidad inmanente, es hacedero afirmar semejante cometido unificador en la historia salvífica apropiado a la Tercera Persona ${ }^{59}$. "Al Espíritu Santo se atribuye la efusión del amor o de la caridad en los corazones de los fieles $(R o m$ 5,5) para trabarlos todos entre sí y con su principio que es Dios. Esta sociedad de almas o de corazones es la Iglesia, siendo su vínculo orgánico de unidad el Espíritu Santo. El cisma de Donato rompia las relaciones del bautizado con el Espíritu Santo, suprimiendo el vínculo de unidad de los hijos de Dios y destruyendo la Iglesia, cuya formación se debe al Espíritu Santo y no a los ministros del primer sacramento. Así se comprende el lenguaje fuerte de san Agustín cuando acusa a los cismáticos de "despedazar la Iglesia", de hacerla fragmentos y de ser cuervos, que se alimentan de cadáveres" ${ }^{60}$.

De lo dicho se infiere, en apelación sinténtica, que Cristo personaliza la originalidad del orden salvífico: es el protosacramento y la razón de la gracia, el auctor sacramenti, su ministro principal y sumo sacerdote. De ahí que los sacramentos de la Nueva Alianza, administrados incluso por cismáticos, herejes y pecadores, ubique recta sunt ${ }^{61}$, -con tal de que quieran hacer lo que hace la Iglesia, añaden los manuales. A Cristo corresponde igualmente la misión de su Espíritu, al que se asigna la infusión de la gracia y de la caridad. $\mathrm{Y}$ El es - concluye la argumentación agustiniana- quien realiza los sacramentos, actualizando visiblemente estos signos de salvación por la Iglesia y en la Iglesia.

59. También el Padre y el Hijo actúan a su modo esta unidad, no ya sólo por la inseparibilidad de las operaciones divinas ad extra de las tres Personas divinas, sino también porque la presencia vitalizadora y unificativa del Espíritu, es presencia del don del Padre y del Hijo.

60. V. CAPANAGA, Agustin de Hipona (Madrid 1974) 90. Cf. In Iohannis evangelium tr. 6,4; Contra litt. Petiliani II, 77,172: "Caritas enim christiana nisi in unitate Ecclesiae non potest custodiri"; Ep. 185,50: "Non est autem particeps divinae caritatis qui hostis est unitatis".

61. Cf. nota 53 . 


\section{Maternidad de la Iglesia y sacramentos}

Al ritmo de la genuina teologia existencial del obispo de Hipona, parece obligado a estas alturas aludir al dinamismo de los sacramentos del lado de la Iglesia, continuadora del hacer redentivo y uno de los factores propuestos que definen la dialéctica sobrenatural de la presente economía de la gracia. La Iglesia-virgen, Esposa indefectiblemente unida al Esposo, representa el prototipo de là unión sacramental, al tiempo que ejemplariza el modo de actuación divina con el hombre ${ }^{62}$. Pero el proceso teológico explicativo adquiere concreción y radicalidad de consecuencia en torno a ese atributo denso de significado de la maternidad. Al predicar de la Iglesia la fórmula vita materque viventium, se enuncia - escribe- su gran misterio (magnum est Ecclesiae sacramentum) ${ }^{63}$. Con "esta afirmación mantiene como punto de partida la unión de Cristo con la Iglesia, la realidad del Cristo total, que fundamenta teológicamente la nueva alegoría y da valor a la expresión "Ecclesia mater" "4.

En una visión dinámica de la historia salvífica cabe, siempre sobre la línea ideológica del Obispo africano, referir a una misma finalidad constitutiva, $\mathrm{y}$ también existencial, las múltiples modalidades indicativas que esclarecen, entitativa y funcionalmente, el influjo efectivo o causalidad de la Iglesia. Cuando se apela, pues, a su maternidad virginal, la alusión apunta no a un concepto idealizado sin contenidos reales, sino a la fórmula explicativa del misterio que interpreta la razón formal del hacer de Cristo a través del tiempo y del espacio. La Iglesia es Madre - la pia Mater Ecclesia-, que nos ha engendrado para la vida sobrenatural ${ }^{65}$. Ella es la Madre que nutre, protege, custodia y guía por las sendas de la virtud a los pere-

62. In Iohannis evangelium tr. 8,4; Enarrationes in Ps. 44,3; 48,8; Serm. 291,6; Ep. 118,33: "Itaque totum culmen auctoritatis lumenque rationis in illo uno salutari nomine atque in una eius Ecclesia recreando et reformando humano generi constitutum est".

63. De nuptiis et concupiscentia II, 4,12. 131.

64. R. PALMERO RAMOS, "Ecclesia Mater" en san Agustín (Madrid 1970)

65. De baptismo VI, 2,3; Ep. 243,8: "Mater Ecclesia, mater est etiam matris suae. Haec vos de Christo concepit, haec martyrum singuine parturivit, haec in sempiternam lucem peperit, haec fidei lacte nutrivit et nutrit": : De sancta virginitate 12,11: "Si harum (virginum) quaeritur mater, Ecclesia est".: De sancta virginitate 2,2: “...Nam Ecclesia quoque et mater et virgo est"; De diversis quaestionibus $83,75,2$ : "...in corpore suo intelligatur haeres, id est Ecclesia, cuius cohaeredes sumus: quemadmodum filii eius matris dicimur, quamvis ex nobis constet"; Serm. 22,10: "Parentes qui nos genuerunt ad vitam, Christus est et Ecclesia... Deus autem pater et mater Ecclesia... generant ad vitam aeternam, quia et ipsi aeterni sunt". 
grinos de Dios que vuelven a la Patria ${ }^{66}$. Es efectivamente Madre la Iglesia, y Madre de la verdad, solícita y vigilante, atenta, traspasada de caridad y amor para con sus hijos; la "única Madre verdadera de todas las gentes, que ofrece su regazo a los no regenerados y amamanta a los generados" ${ }^{67}$. Y la formulación definitiva, llena de expresividad y última del principio, que propone san Agustín en el De sancta virginitate: "La Iglesia, en los santos que han de poseer el reino de Dios, ciertamente es, según el espíritu, Madre total de Cristo, Virgen total de Cristo" ${ }^{68}$.

Con igual fuerza expositiva y determinación de postulado describe la conveniencia y necesidad de que la Iglesia sea Madre, dando a luz por el bautismo a los que lleva en sus entrañas ${ }^{69}$. Porque como el heredero temporal de un padre que es hombre nace de una madre carnal, tiene, en cambio, que nacer del seno de la Iglesia quien nace para la herencia inacabable de un Padre que es Dios. El padre mortal engendra de su esposa un hijo que será su sucesor; mas Dios engendra por la Iglesia, no un hijo que le suceda, sino hijos que vivan eternamente con $\mathrm{El}^{70}$. Este tema, punto culminante $\mathrm{y}$ diferenciador de la doctrina eclesial agustiniana, configura el círculo ideológico de su pensamiento que potencializa proyectado sobre la realidad existencializada de la Mater Ecclesia ${ }^{71}$.

Concretamente, el concepto de la fecundidad virgen traduce a términos prácticos la idea de la mediación universal de la Iglesia - Madre de muchos hijos ${ }^{72}$-, reveladora del carácter absoluto de la mediación de Cristo, de la que participa su Cuerpo. La Iglesia, Espo-

66. Quaestiones Evang. 2,2. Cf. H. DE LUBAC, Meditación sobre la Iglesia (Bilbao 1964) 245-246.

67. Ep. 23,4 .

68. De sancta virginitate 6,6: "La maternidad virginal de la Iglesia no es, por otra parte, un concepto idealizado sin valor real, sino la fórmula explicativa del misterio que interpreta la razón formal del hacer de Cristo mediante la Iglesia": S. FOLGADO FLOREZ, "La espiritualidad eclesial y la Virgen": Estudios Marianos 34 (1970) 123.

67. In Iohannis evangelium tr. 12, 2-3.

70. In Iohannis evangelium tr. 12,5: "Si propter haereditatem patris hominis temporalem nascitur, nascatur ex visceribus matris carnalis: si propter haereditatem patris Dei sempiternam, nascatur ex visceribus Ecclesiae. Generat per uxorem filium pater moriturus succesurum: generat Deus de Ecclesia filios non succesuros, sed secum mansuros".

71. San Agustín concluye la necesidad de tener a la Iglesia como Madre, para ser verdaderos hijos de Dios: "Nec habebit Deum Patrem, qui Ecclesiam noluerit habere Matrem; nihilque ei valebit quod credidit, vel fecit tanta bona sine fine summi boni. Ecclesia mater est spiritualis Ecclesia sponsa Christi est gratia dealbata, pretioso sanguine dotata. Totum possidet quod a viro suo accepit in dote": De symbolo ad cat. 4,13; cf. también Serm. 216,8; Serm. 244,1.

72. De unitate Ecclesiae 7,19: "Unde autem multos filios esse habitura...". 
sa de Cristo y Madre Virgen de los cristianos, que brotó del costado abierto del Redentor ${ }^{73}$ y forma una sola cosa con El, es, deciamos antes, el adiutorium simile sibi, principio sobrenatural de salvación semejante a Cristo y de parecida dignidad. No olvidemos a este respecto que la operación del Paráclito, orientada a la incorporación de todos los descendientes de Adán en la unidad de Cristo ${ }^{74}$, sólo es actuante y valedera en el contexto articulado, eclesial del Cuerpo místico. La justificación no es posible, si no somos verdaderamente vivificados por el Espíritu de Cristo en la Iglesia y mediante la Iglesia, depositaria y administradora de la salus inherente a los sacramentos $^{75}$. Con toda claridad lo subraya incluso el hecho a nivel de la sobrenaturalización activa de la persona ineludible de que los hombres precisan ser purificados por el sacramento y la caridad de los fieles, incorporándose así al Cuerpo de Cristo, que es la Iglesia, si han de compartir solidarios los beneficios y gracias del Mediador ${ }^{76}$. $\mathrm{Y}$ es ese estar actuante la caritas fidelium en la justificación, consecuente al sacramento, ley y circunstancia exigida para que el acontecimiento inicial salvífico - desde la generación in utero Ecclesiae - sea sinónimo de "cristificación", de concorporarse al Cuerpo de Cristo y articularse en miembro suyo, de radical integración de la nueva creatura en la comunidad eclesial como presupuesto condicionante para llegar a la vida y salvación eterna ${ }^{77}$.

De cualquier forma, la administración de los sacramentos y la predicación evangélica concretan de manera inequívoca la característica de la actividad maternal de la Iglesia, dado que el hombre se abre a la gracia en una comunidad de vida, a la que se integra socialmente recibiendo aquellos bienes. La forma sacramenti se corresponde con el bautismo; con el evangelio, la forma iustitiae. Son dos modos complementarios de una misma misión hecha práctica y ejercicio per verbum et sacramenta ${ }^{78}$. La palabra y el sacramento

73. Enarrationes in Ps. 116,7: De symbolo ad cat. 2,15.

74. Contra Cresconium II, 13,16; Serm. 71,20,33. Cf. A. POPPI, Lo Spirito Santo $e$ il Corpo Mistico in S. Agostino (Roma 1955) 24.

75. Serm. ad Caesariensis Eccl. plebem 6: "Extra Ecclesiam catholicam totum potest praeter salutem. Potest habere honorem, potest habere sacramentum, potest cantare Alleluia, potest respondere Amen, potest Evangelium tenere, potest in nomine Patris et Filii et Spiritus Sancti fidem tenere et habere et praedicare: sed nusquam nisi in Ecclesia catholica salutem poterit invenire".

76. De peccatorum meritis et remis. I, 26,39.

77. De peccatorum meritis et remis. III, 4, 7-8.

78. Contra litt. Petiliani 56,68: "Et si hoc de evangelio recte dicitur, quanto magis de baptismo dicendum est, quod ita pertinet ad evangelium, ut sine illo quidem ad regnum caelorum nemo perveniat, sed si accedat sacramento iustitia...! Forma sacramenti datur per baptimum, forma iustitiae per evangelium: alterum sine altero non perducit ad regnum caelorum". 
dan relieve al cometido maternal, salvífico, de la Iglesia. Entre la predicación del evangelio, la palabra, que impresiona la interioridad del hombre y mueve los corazones a la conversión, y el gesto sacramental de sumergirse en el agua, el signum sacrum, que la significa y lleva a su término, realizándola, existe una estrecha y esencial conexión. Porque sólo, cuando a la forma sacramenti - celebración ritual del sacramento- acompaña la forma iustitiae - su fruto espiritual simbolizado aquí por el evangelio-, producirá el bautismo los efectos saludables de santidad y de gracia ${ }^{79}$. "Nuestro alimento cotidiano sobre la tierra - escribe el Santo- es la palabra de Dios; que continuamente se administra en la iglesia: nuestra recompensa, después del trabajo, se llama vida eterna. En este nuestro pan de cada día puede asimismo, entenderse lo que los fieles reciben o recibiréis también vosotros una vez bautizados" 80 . Con el bautismo los "competentes" recibirán la salus, "quae est propria bonis", en tanto que los sacramentos son comunes "et bonis et malis" 81 .

Es claro que el fundamento teológico de este capítulo de la eclesiología agustiniana se refiere a la mediación maternal de la Iglesia, digna de ser amada porque a todos nos ha engendrado para la vida eterna ${ }^{82}$. Teoría que adquiere luego consistencia y volumen temático a través del análisis conceptual del nascendi principium, el sacramento de la regeneración, con el que se vinculan los beneficios iniciales recibidos con el bautismo, tales como el nuevo nacimiento o regeneración, el perdón de los pecados, la unión con Dios, la incorporación a Cristo e integración en la "societas sanctorum". Idénticas deducciones de signos afirmativo engloba la explicación de los otros beneficios adjuntos al vivendi alimentum, beneficios prestados con igual solicitud de Madre por la Iglesia, empeñada en fortalecer y perfeccionar el existir cristiano hasta su perfección definitiva ${ }^{83}$.

79. Traités Anti-donatistes, III, 753, nota 7.

80. Serm. 56,10 .

81. De baptismo VII, 33,65: “...Sacramentum gratiae dat Deus etiam per malos; ipsam vero gratiam non nisi per se ipsum vel per sanctos suos": De baptismo V, 21,29. Los catecúmenos "competentes dicebantur, quoniam materna viscera, ut nascerentur petendo pulsabant": Serm. 228,1. "Competentium vocabulum non aliunde quam de simul petendo atque unum aliquod appetendo compositum est": Serm. 216,1.

82. "Ama matrem tuam, sed noli super Ecclesiam, quae te genuit ad vitam aeternam. Denique ex ipsorum parentum amore perpende quantum diligere debeas Deum et Ecclesiam. Si enim tantum diligendi sunt qui genuerunt moriturum, quanta caritate diligendi sunt qui genuerunt ad aeternitatem venturum, in aeternitate mansurum": Serm. 344,2.

83. "Comprende los que llama el Santo "manjares espirituales", que se reducen a la doctrina de la fe, la moral y los sacramentos, en particular la divina eucaristía. Alude también el Santo a los torrentes de delicias con que la Iglesia 
En la presente economía de la gracia y sus condicionamientos existenciales, la misma naturaleza de las cosas que son asi urge apriorísticamente la conveniencia de la función maternal de la Iglesia, puesta además de relieve por la ejemplarización formulada desde la analogía entre el primer nacimiento natural ex masculo et femina y el segundo sobrenatural ex Deo et Ecclesia ${ }^{84}$. Importa a este respecto señalar cómo todas las variantes declarativas del principio incluyen a la Iglesia en el enunciado que notifica y dice las causas actuantes de la regeneración. $Y$ nacer de la Iglesia equivale a revestirse de Cristo, a comenzar una vida nueva a partir del bautismo mediante la gracia.

Por otra parte, san Agustín acentúa de continuo la correspondencia que, como efecto sacramental, se establece entre la "cristificación", no sólo bajo la formalidad ontológica (in forma sacramenti) sino también dinámica (in opere exempli), y la incorporación al organismo sobrenatural de vida, la "societas sanctorum" ${ }^{85}$. Lo que delimita el verdadero contorno maternal de la Iglesia en progreso y tendencia de plenitud católica, que va totalizándose como Cuerpo de Cristo a medida que actúa su misión de Madre. Misión recapituladora de nuevas asimilaciones y logros redentivos hacia la ultimación y plenificación del Cristo total, el "varón perfecto". Esto presupone a la hora de valorar las actividades salvíficas concretas, la consideración obligada de la doctrina general agustiniana sobre el Cuerpo místico, cuyo esquema teológico jerarquiza las funciones y define las modalidades. Con ello queremos decir que, si Cristo concede a la Iglesia la facultad de colaborar activamente en las acciones sacramentales, lo hace actualizando su condición primaria de Cabeza. Por eso también, si los sacramentos han de entenderse como "autorrealizaciones" de la Iglesia, conviene en cualquier caso precisar el carácter y sentido de la atribución referida a la plenitudo Christi, la Iglesia que es Cuerpo y plenitud de Cristo, unida a El $\mathrm{y}$ dependiente de la virtualidad de la Cabeza.

Es este un punto clave que se sitúa en el centro mismo de la eclesiología agustiniana. Sin duda que se trata de una visión con-

regala a los que fielmente la siguen en su doctrina, y por tales pueden, sin duda, entenderse los frutos y consolaciones, que no faltan en los que se mantienen fieles. $\mathrm{Y}$ pueden entenderse también los dones místicos o gracias muy elevadas que Dios reserva para sus amigos": V. CAPANAGA, Agustín de Hipona, 162.

84. Serm. 121,4 .

85. Serm. 37,2,6. Șer miembros de la Iglesia visible se consigue únicamen_ te con el sacramento, pero la incorporación al Cuerpo místico es fruto del bautismo y también del martirio por Cristo: "Nemo fit membrum Christi, nisi aut baptismate in Christo, aut morte pro Christo": De anima et eius origine $\mathrm{T}, \mathbf{9 , 1 0}$. 
creta, interesada y comprometida de la Iglesia y de los sacramentos, realizaciones y expresión de la propia Iglesia. El Cuerpo de Cristo lo configuran todos aquellos que la Ecclesia Mater engendra como hijos, incorporados misteriosamente a su maternidad desde el momento que contribuyen a transmitir la nueva vida a los otros. Los cristianos forman con Cristo una unidad viviente, capaz de comunicar su propio modo de ser y de existir. Cuando alguien recibe el sacramento, los fieles que integran el Cuerpo de Cristo se convierten en madre de Cristo. Es toda la Iglesia, comunidad de los creyentes santificados y vivificados por el Espíritu de Cristo, la que confiere su vida al neófito. Porque la Iglesia entera da a luz a todos y cada uno de los miembros de Cristo ${ }^{86}$.

Junto al rito sacramental, contribuye también al nacimiento de los hijos de Dios la caridad de la Iglesia, la caritas fidelium que dice san Agustín. Todo el Cuerpo de Cristo engendra, pues, a los miembros de Cristo y coopera activamente al sacramentum nativitatis. "La característica de la Iglesia en cuanto Madre-Virgen consiste en que sus miembros, engendrados en ella, se incorporan a su maternidad. Como miembros son hijos de la Iglesia, pero ellos mismos constituyen y forman la Iglesia en cuanto comunidad. La maternidad de la Iglesia no es una cualidad que radique individualizada en cada uno de sus miembros. Es la Iglesia total - unicus populus et una Ecclesia - quien posee la función de ser Esposa y Madre virgen que engendra continuamente nuevos hijos, incorporados a su vez a Cristo como participantes de su fecundidad sobrenatural. Todos, miembros activos de la Iglesia ${ }^{87}$, están capacitados y causan la regeneración a la gracia en nombre de la comunidad, ya que siempre es ésta -la Iglesia - la que actúa y ejercita el poder de Dios, cuya realización sacramental compete por voluntad expresa de Cristo a determinados miembros responsables. Por eso, el ministro del sacramento hace y practica lo que preceptúa la Iglesia, siendo la comunidad del Cuerpo místico, la totalidad de los santos, el

86. Ep. 98,5: "Tota hoc ergo mater Ecclesia, quae in sanctis est, facit, quia tota omnes, tota singulos parit"; cf. también Quaestiones Evang. 1,18: "Quod ipsis rogantibus filii sanantur, intelligenda est Ecclesiae persona, quae sibi est et mater et filii: nam simul omnes, quibus constat Ecclesia, mater dicitur; singuli autem iidem ipsi filii appellantur"; Serm. 99,9: "Deus ergo habitat in templo sancto suo, hoc est, in sanctis suis fidelibus, in Ecclesia sua: per eos dimittit peccata, quia viva templa sunt"; De sancta virginitate 5,5: "Mater eius est tota Ecclesia, quia membra eius, id est, fideles eius per gratiam ipsa utique parit. Item mater eius est omnis anima pia, faciens voluntatem Patris eius fecundissima caritate, in is quos parturit, donec in eis ipse formetur".

87. Const. dogm. sobre la Iglesia, núm. 7; Decreto sobre el apostolado de los seglares, núms. 1-2. 
factor único que responde a la llamada de Dios y engendra, unida a Cristo, la vida sobrenatural" ${ }^{88}$.

En la teoria eclesiológica agustiniana adquieren, según eso,importancia decisiva las reiteradas apelaciones a los términos de "comunión", "unidad", "vínculo de la paz", etc., puesto que, referidos directamente al propio ser existencial de la Iglesia, descubren la necesaria condición connotativa de su fecundidad. Sólo bajo el supuesto de la communio ecclesialis tienen sentido y alcanzan su plena indicación teológica frases tan cargadas de significado e intencionalidad como la de "uterus Ecclesiae, fons baptismi" 29: La expresión, al igual que otras de idéntico signo, recoge la exigencia de la Unidad Católica para que, vinculada a Cristo (la Iglesia) y fecundada por el Espíritu, perdone los pecados y presencialice saludablemente los beneficios de la redención entre los hombres ${ }^{\infty}$.

\section{Sujeto eclesiológico de las acciones sacramentales}

Que la Iglesia ejercita un desempeño propio en la constitución del signo sacramental es indudable. Mediadora maternal de la gracia, la Iglesia de Cristo, la Católica, es el verdadero sujeto eclesiológico de las operaciones salvíficas, incluidos los sacramentos. Dada la estructura del orden de la gracia, existe un imperativo de acción eclesial, límite inmediato en la serie de mediaciones que actúan la validez y eficacia del hecho sobrenatural. El bautismo -explicita san Agustín - es de la Trinidad, es de Cristo, es de la Iglesia ${ }^{91}$. Y, como aclamación polémica de la tesis, afirmará sin paliativos la pertenencia a la Católica de cuanto hay de bueno y de verdad cristiana en las confesiones disidentes ${ }^{22}$. Porque, si es cierto que los cismáti-

88. S. FOLGADO FLOREZ, La espiritualidad eclesial y la Virgen, 105.

89. De baptismo II, 6,8: "Hos omnes catholica unitas materno sinu complectitur"; De peccatorum meritis et remis. I, 25,38: "Quod per sacramentum baptismatis in parvulis non dubitat mater Ecclesia, quae cor et os maternum eis praestat"; Serm. 216,7: "Ecce uterus matris Ecclesiae, ecce ut te pariat, atque in lucem fidei producat, laborat in gemitu suo"; Serm. 119,4: "Vulva matris aqua baptismatis". Cf. R. PALMERO RAMOS, "Ecclesia Mater" en san Agustín, 147; L. VILLETE, Foi et Sacrament. Du Nouveau Testament a saint augustin (Paris 1959) 248-250.

90. In Ep. Iohannis ad Parthos 3,$1 ; 2,4$; De agone christiano 30,32; Enarrationes in Ps. 126,8; Enarrationes in Ps. 57,5; Enchiridion 17,65.

91. Contra litt. Petiliani II, 21,57; Ep. 23,4.

92. "Malum dissensionis, schimatis, haeresis malum suum habent, bona vero quae in illis agnoscimus non sunt sua. Domini nostri habent bona, Ecclesiae habent bona. Baptismus non est ipsorum, sed Christi": Serm. ad Caesariensis Eccl. plebem 3. Cf. E. LAMIRANDE, La situation écclesiologique, 30-32. 
cos y opositores de la unitas tienen "nuestros sacramentos, nuestras escrituras, nuestro 'Amén', nuestro 'Alleluia', nuestro símbolo y muchos de ellos hasta nuestro bautismo" ${ }^{93}$, se trata, sin embargo, de bienes confiados por Cristo a su Iglesia y que la Católica reclama en patrimonio y administra como propiedad legítima suya ${ }^{94}$.

A pesar de las limitaciones morales e indignidad de los ministros, el sacramento garantiza su validez siempre que se mantenga a salvo la auténtica intencionalidad eclesial. La Iglesia en si misma y en cuanto tal es elemento activo, agente y mediadora en la constitución del signum sacrum desde la perspectiva y cometido que le son propios. No es posible, en consecuencia, olvidar que toda la virtud regenarativa y santificadora proviene de Cristo-Cabeza que actúa su eficacia sacramental al amparo de la "societas sanctorum", la unidad mística que los creyentes articulan por el Espíritu en un solo Cuerpo. Los sacramentos son acontecimiento salvífico. Algo que, según las determinaciones divinas, se conforma y cumple dentro de la Iglesia y mediante la Iglesia ${ }^{95}$.

La concepción agustiniana de los sacramentos comporta, indudablemente, una soteriología eclesial que rebasa el nivel humano de la mera ejecución del rito. Con tal de que se cumpla las condiciones impuestas por Cristo mismo para la existencia y constitución formal del sacramentum, nada importa luego para su validez la dignidad o indignidad del administrante. El sacramento es obra y acción de Cristo, y de Cristo recibe su valor ${ }^{96}$, aunque en la Iglesia y dado por la Iglesia. Una vez cumplido el consummatum est de la obra salvífica, cruz-resurrección-misión del Espíritu, el misterio de gracia, que está realizado y continuará realizándose hasta el fin de la historia, no se efectúa ya sin la Iglesia y al margen de la Iglesia, adiutorium

93. Serm. 37,27. Cf. también Serm. ad Caesariensis Eccl. plebem 6: "Extra catholicam Ecclesiam totum potest...": cf. nota 75.

94. Contra Cresconium II,10,12: "Prorsus agnoscit in vobis Ecclesia cuncta queae sua sunt, nec ideo non sunt eius quia et apud vos inveniuntur. Apud vos quippe aliena sunt". De ahí que sea siempre la Iglesia católica el sujeto maternal de la regeneración: "Itaque est una Ecclesia, quae sola catholica nominatur; et quidquid suum habet in communionibus diversorum a sua unitate separatis, per hoc quod suum in eis habet, ipsa utique generat, non illae. Neque enim separatio earum generat, sed quod secum de ista tenuerunt: quod si et hoc dimittant omnino non generant. Haec itaque in omnibus generat sacramenta retinentur, unde possit tale aliquid ubicumque generari: quamvis non omnes quod generat ad eius pertineant unitatem": De baptismo I, 10,14.

95. Cf. R. SCHULTE, Los sacramentos de la Iglesia, 99.

96. Cf. Ch. BOYER, Sant'Agostino $e$ i problemi dell'ecumenismo (Roma 1969) 66. 
Christi y Madre de los cristianos que actualiza de continuo su influjo en las almas. De manera axiomática enuncia san Agustín la necesidad de la Iglesia para la salud, que es originariamente la misma necesidad de Cristo: fuera de la unitas, del Cuerpo de Cristo que es la Iglesia, no vive la caridad y el Espíritu no vivifica ${ }^{97}$. Supuesta la ampliación teológica del principio, insinuada ya por el Obispo de Hipona, está el hecho incuestionable de que el camino normal para la salvación es la Iglesia y de que el Espíritu de Cristo en su acción sobrenatural supone y crea la pertenencia a la Iglesia ${ }^{98}$. La verificación teológica de la tesis más que detenerse en aclaraciones de tipo jurídico y externas, apunta directamente a la descripción de la naturaleza misma de las cosas. Si la Iglesia es el protosacramento de la presencia de la salud en el mundo, lo es en la unidad; si el bautizado recibe la gracia y el Espíritu de Cristo, es dentro de la Iglesia e incorporándose a su Cuerpo. He aquí la frase sintesis reveladora de sus convicciones y conclusión de su doctrina: "Si vultis vivere de Spiritu Sancto, tenete caritatem, amate veritatem, desiderate unitatem" ${ }^{99}$.

Esto supone una fundamentación eclesiológica que supera el nivel de lo institucional jerárquico para centrarse de lleno en el misterio de unidad que configuran los fieles constituidos en Iglesia ${ }^{100}$. Y no es que san Agustín desestime la función y ministerio de los obispos. Su teología intenta de hecho ser equilibrada sin glorificar hasta unos límites impropios y no correspondientes el cometido de la autoridad. Los sacramentos son de Cristo y de la Iglesia, nunca de la jerarquía que cumple sencillamente un encargo ministerial. Las operaciones sacramentales están, por un lado, referidas a Dios y, por otro, a la Iglesia en cuanto tal. Dios -Cristo o su Espirituconstituye el sujeto principal de la acción santificadora, siendo la Iglesia - no el colegio de los obispos - el punto exclusivo de apelación que explica la maternidad espiritual y la infalibilidad en la fe: el sujeto eclesiológico que perdona los pecados. Y lo es en tanto que realiza y encarna la Unitas, la Pax y la Caritas, bajo el influjo vita-

97. Ep. $185,11,50$.

98. “...Oggi e dottrina sicura che per la salvezza basta il sincero desiderio anche solo implicito, di appartenere alla vera Chiesa di Christo, o anche divolersi conformare a la divina volontà": Ch. BOYER, Sant'Agostino, 69.

99. Serm. 268,2.

100. San Cipriano, conocedor de esta teología, ponía, sin embargo, "Ie fondement ecclésiologique de l'unité dans la communion, et donc dans la concorde, des éveques ("Ecclesia super episcopos constituitur": Ep. 33,1). Les Donatistes avaient, aux aussi, une conception de l'Eglise tres liée au sacerdoce et a l'épiscopat": Y. M.- J. CONGAR, Introduction général, 102. 
lizante y presencia cristificadora del Espíritu. Para san Agustín, pues, Dios, autor de la gracia, es el verdadero sujeto (divino) de la virtud y eficiencia espiritual de los sacramentos; mientras que la Iglesia (la sola Iglesia de Cristo) actúa como sujeto eclesiológico real y único de las acciones sacramentales ${ }^{101}$.

Hábil e ingenioso interpretador de los símbolos bíblicos, el obispo de Hipona dibuja las líneas "eje" de su pensamiento sobre el particular en torno al significado tipológico de la paloma (columba) de grande aplicación incluso para la espiritualidad de cualquier tiempo, porque cumplica y hace participar a los cristianos en los ideales e inquietudes, intereses y sentimientos maternales, regenerativos de la Iglesia. Los rasgos típicos de la paloma le ayudan a desarrollar una simbología eclesial sumamente expresiva, puesto que al amparo de ella acentúa y pone de relieve el valor concreto y el alcance efectivo de la unidad, santidad y catolicidad de la Iglesia-Madre, gemido y arrullo, caridad universal que quiere unir a todos los hombres y a todos mejorarlos por el amor ${ }^{102}$.

El sujeto propio que a través de los sacramentos ejerce una función maternal activa es la Columba, símbolo de la Iglesia-Esposa de Cristo "sine macula et ruga" ${ }^{103}$. A la Columba compete el poder de las llaves ("Columba tenet, Columba dimittit"). Sobre lo aparente y externo de las acciones sacramentales, se sitúa la actuación más íntima y profunda, la más eficaz y renovadora, la más eminente, en definitiva, por la que Dios funda y causa la caridad en los fieles, cuyo resultado es la Ecclesia in sanctis, la Unidad y lo que con ella se corresponde, a saber el perdón de los pecados ("Unitas tenet, Unitas dimittit"). Válida y realmente bautizados —los que están lejos y se empeñan en permanecer en la herejía-, no reciben, sin embargo, los frutos de la salvación inherentes al sacramento mientras no entren en la Paz; lo que significa aceptar la Unidad de Cristo e integrarse en la Columba, que no cesa de gemir por ellos ${ }^{101}$.

101. Cf. Y. M.- J. CONGAR, Introduction général, 103-105.

102. "Une fois de plus, Augustin a su joindre, dans une synthèse simple, forte et cohérente, non seulement les images et les idées, non seulemnent les thèmes bibliques et ses catégories philosophiques, mais tous les aspects différents que portait, traditionnellement, ce symbole de la colombe: Paix, communauté, Saint-Esprit, pureté, gémissements, fidélité du couple, et meme signification étymologique du nom de "Simon, fils de Jona", "filius columbae": Y. M.- J. CONGAR, Introduction générale, 105 ; cfr. también V. CAPANAGA, Agustin de Hipona, 92-94.

103. In Iohannis evangelium tr. 6, donde desarrolla con amplitud el símbolo de la columba.

104. Como síntesis del pensamiento agustiniano, citamos el siguiente texto: "Ergo si personam gerebant Ecclesiae (los Apóstoles), et sic eis hoc dictum est 
San Agustín identifica la Columba con la "societas sanctorum", la Iglesia que se compone "de los cristianos verdaderos, de los fieles animados por la caridad y viviendo según el Espíritu, no según la carne. La Calumba personaliza a los santos, unidos por la caridad en una unidad que, en la medida de lo posible, es el sujeto eclesiológico de las operaciones santificantes, y sobre todo del perdón de los pecados ${ }^{105}$. Esta es la Iglesia una y también única..." ${ }^{106}$. La paloma es el símbolo de la paz, de la esposa única y fiel, bella, inocente y pura, la que gime y suspira por un mundo libre del pecado y de la discordia donde reine la caridad, la unión de los corazones y la tolerancia de unos para con otros ${ }^{107}$. Representa, consiguientemente, el lugar de actuación del Espíritu y de fructificación del sacramento. La Columba es el sujeto eclesiológico de la remisión de los pecados, posibilitada solamente por la Caritas en la Unitas y la Pax, sinónimos y aspectos de la única y sola Iglesia de Cristo: la Católica ${ }^{108}$.

El interés sacramentológico de san Agustín, concluimos, tiene todavía hoy una vigencia total, cuando se analiza el conjunto doctrinal de su soteriología. Porque si concreta mejor que nadie la interpretación y explicación del sacramento como signum sacrum, incorpora al concepto, también con claridad desconocida hasta entonces, esa otra formalidad más profunda y determinante de acontecimiento salvífico (la res) en la auténtica dimensión de Cristo y de la Iglesia. Para él, el signo sacramental, al margen de la cristología y

(Io 20, 22-23), tanquam ipsi Ecclesiae diceretur; pax Ecclesiae dimittit peccata, et ab Ecclesiae pace alienatio tenet peccata, non secundum arbitrium hominum, sed secundum arbitrium Dei et orationes sanctorum spiritualium, qui omnia iudicant, ipsi autem a nemine iudicantur 1 Cor 2,15). Petra autem tenet, petra dimittit: columba tenet, columba dimittit: unitas tenet, unitas dimittit. Pax autem huius unitatis in solis bonis est, vel iam spiritualibus, vel ad spiritualia concordi obedientia proficientibus: in malis autem non est, sive foris tumultuentur, sive intus cum gemitu tolerentur, et baptizent et baptizentur. Sicut autem isti qui intus cum gemitu tolerantur, quamvis ad eamdem columbae unitatem, et ad illam Ecclesiam non habentem maculam aut rugam aut aliquid huiusmodi" (Ef 5,27), non pertineant...": De baptismo III, 18,25.

105. Esto no quiere decir que san Agustín propugne la existencia de una doble Iglesia. Con abundancia de datos y habilidad dialéctica defiende que la Iglesia huius temporis, hasta el día de la separación definitiva, es permixta. No se trata, pues, de dos Iglesias distintas, sino de dos géneros de hombres antropológica y espiritualmente distintos dentro de la misma Iglesia. De cualquier forma, existe el problema de cómo san Agustín concibe la pertenencia de los pecadores a la Iglesia.

106. Cf. Y. M.- J. CONGAR, Introduction générale, 106-107.

107. "Veni ubi est columba" (In Iohannis evangelium tr. 6,15) es el grito dolorido que san Agustín lanza a los disidentes y alejados de la Iglesia.

108. Serm. 295, 2: "“Has claves non unus homo, sed unitas accepit Ecclesiae... columba ligat, columba solvit, aedificium supra petram ligat et solvit". Cf. De baptismo III, 17,22. 
sin una referencia explícita a la Ecclesia, sujeto de la mediación maternal, carece de sentido, no expresa al menos todo el significado y contradice otros puntos fundamentales de su teologia ${ }^{109}$.

S. Folgado Flórez, OSA.

Universidad María Cristina

EL ESCORIAL - MADRID

109. La sacramentología agustiniana es, en consecuencia, algo más que la simple definición (sacrum signum), como quiere hacer ver R. SCHULTE, Los sacramentos de la Iglesia, 94-95. 